\title{
Что означает понятие «суверенитет» в цифровом мире?'
}

\author{
С. Кутюр, С. Тоупин
}

Кутюр Стефан - доцент, Глендон-колледж, Йоркский университет, 2275 Бэйвью-авеню, Торонто, Онтарио, Канада - M4N 3M6; E-mail: stephane.couture24@gmail.com

Тоупин Софи - аспирантка факультета истории искусства и теории коммуникации Университета Макгилла (Монреаль, Канада).

Статья посвящена особенностям употребления понятия «суверенитет» в реалиях цифровизации. Рассматриваемое понятие все чаще используется для описания всевозможных форм независимости, контроля и автономии в отношении элементов цифровой инфраструктуры, технологий и данных. Представленный анализ основывается на результатах предшествующих и текущих исследований (с привлечением специалистов и экспертов), в рамках которых авторы обнаруживают примеры применения понятия «суверенитет» для описания технологических процессов, которые существенно отличаются от деятельности государств. Авторы рассматривают ряд публикаций, итобы продемонстрировать разнообразие существующих подходов, принятых в рамках различных групп и объединений. Наглядно показано, что хотя в отдельных случаях понятие «суверенитет» используется для установления некой формы коллективного контроля над иифровой информацией и (или) инфраструктурой, возможны и совершенно иные подходы к определению рассматриваемого понятия.

Ключевые слова: суверенитет данных; цифровой суверенитет; дискурс; коренное население; управление Интернетом; национальные государства; социальная мобильность; технологический суверенитет

Для цитирования: Кутюр С., Тоупин С. (2020) Что означает понятие «суверенитет» в цифровом мире? // Вестник международных организаций. Т. 15. № 4. C. 48-69 (на русском языке). DOI: 10.17323/19967845-2020-04-03

\section{Введение}

Целью настоящей статьи является изучение особенностей применения понятия «суверенитет» в цифровой сфере. Определение «цифровой» в данном контексте опирается на распространенное толкование, которое подразумевает технологии, инфраструктуру и данные, основанные на или используемые при помощи электронных компьютерных технологий [Peters, 2016, p. 94]. В последние годы наблюдается увеличение случаев использования понятия «суверенитет» в связке с такими терминами, как «цифровой», «данные» и «технологии» (табл. 1). Важно напомнить, что понятие «суверенитет» теперь

${ }^{1}$ Couture S., Toupin S. (2019) What does the notion of "sovereignty" mean when referring to the digital? // New Media \& Society. Vol. 21. No. 10. P. 2305-2322 (First Published August 12, 2019). Статья с разрешения издательства SAGE переведена А.А. Игнатовым, м.н.с. Центра исследований международных институтов Российской академии народного хозяйства и государственной службы при Президенте Российской Федерации (РАНХиГС). 
использует множество акторов: от глав государств и специалистов в области изучения коренных народов и до представителей общественных движений и околоанархических «технических сообществ». Все эти акторы применяют совершенно разные подходы для рассмотрения понятия «суверенитет» в контексте проблематики торгового протекционизма, многостороннего управления Интернетом или защиты от вмешательства государства в частную жизнь.

В данной статье мы рассматриваем примеры того, как меняется концепция суверенитета при его применении различными акторами в отношении «цифровой» проблематики. Представленный анализ основан на результатах соответствующих полевых исследований и опыте участия в работе объединений технических специалистов и сетевых сообществ, декларирующих приверженность идеям социальной справедливости [Couture et al., 2016; Couture, 2018; Toupin, 2014]. В последние годы появилось множество примеров, когда представители указанных групп использовали понятие «технологический суверенитет», подразумевая разработку цифровых технологий и создание цифровой инфраструктуры с использованием свободно распространяемого программного обеспечения (ПО), серверных устройств и технологий шифрования как на коллективной основе, так и в одиночку [Beltrán, 2016; Haché, 2014a; 2014b; 2017; Nitot, 2016]. Подобный подход представляет для нас особый интерес, поскольку существенным образом отличается от иных интерпретаций, основанных на приоритизации роли государства или политической компоненты суверенитета. Сам факт использования понятия «суверенитет» представителями данных сообществ для нас удивителен, ведь сами они характеризуют сущность суверенитета именно с позиции государства, а не как отражение некой степени «автономности». Приняв данное обстоятельство во внимание, мы задались целью выяснить, кто, как и почему использует понятие «суверенитет». Именно непосредственный опыт взаимодействия с общественными активистами и техническими специалистами подтолкнул нас к рассмотрению данного понятия с позиций широкого круга акторов. Мы хотим получить ответ на вопрос о том, почему те или иные группы используют понятие «суверенитет», рассуждая о технологиях. Хотя изначально указанный материал опирался на опыт непосредственного взаимодействия с представителями тех или иных групп интересов, основным методом, который мы использовали при подготовке данной статьи, стал дискурс-анализ, применение которого позволило продемонстрировать все разнообразие подходов к использованию понятия «суверенитет» в контексте цифровых технологий и цифровизации, особенно с позиции разнообразных общественных организаций, например, государств, общественных движений или коренных народов.

Таблица 1. Частота использования понятия «суверенитет» в работах, посвященных проблематике цифрового развития (с использованием инструментов ProQuest Central)

\begin{tabular}{|l|c|c|c|c|c|c|}
\hline & \multicolumn{2}{|c|}{ Суверенитет данных } & \multicolumn{2}{c|}{ Технологический суверенитет } & \multicolumn{2}{c|}{ Цифровой суверенитет } \\
\cline { 2 - 7 } & $\begin{array}{c}\text { Академические } \\
\text { статьи }\end{array}$ & $\begin{array}{c}\text { Иные виды } \\
\text { публикаций }\end{array}$ & $\begin{array}{c}\text { Академические } \\
\text { статьи }\end{array}$ & $\begin{array}{c}\text { Иные виды } \\
\text { публикаций }\end{array}$ & $\begin{array}{c}\text { Академические } \\
\text { статьи }\end{array}$ & $\begin{array}{c}\text { Иные виды } \\
\text { публикаций }\end{array}$ \\
\hline До 2011 г. & 0 & 23 & 12 & 81 & 0 & 6 \\
\hline $2011-2014$ гг. & 18 & 794 & 6 & 101 & 2 & 49 \\
\hline $2015-2018$ гг. & 89 & 2459 & 20 & 131 & 22 & 239 \\
\hline
\end{tabular}


Данная статья не претендует на исчерпывающий обзор всех опубликованных материалов по рассматриваемой проблематике. Основу работы составляют отобранные публикации, которые позволяют получить компетентное представление о сущности понятия «суверенитет» и особенностях его применения. Кроме того, следует отметить, что выборка материалов ограничивается публикациями на английском языке и ссылками на отдельные франкоязычные издания. Мы отбирали исходный материал при помощи реферативных баз Google Scholar и WorldCat, а также библиотечных фондов Университета Макгилла и Йоркского университета (Канада). Кроме того, для изучения примеров использования рассматриваемого понятия в онлайн-публицистике были задействованы поисковые алгоритмы Google. Изначально объектом поиска выступало только понятие «технологический суверенитет», однако в дальнейшем в поисковый запрос были включены такие элементы, как «цифровой суверенитет», «сетевой суверенитет», «суверенитет данных», «частотный суверенитет», «компьютерный суверенитет» и «информационный суверенитет». В итоге мы отобрали около 50 документов, включая академические статьи и монографии. Изучение отобранных материалов позволило выделить некоторое количество смысловых категорий, представляющих несколько типов акторов: национальные государства, коренные народности, гражданское общество, общественные организации, а также отдельные личности. После первичной категоризации мы расширили выборку по методу «снежного кома». В дальнейшем мы добавили еще одну категорию, которая отражает актуальную по сей день точку зрения, согласно которой Интернет и информационные сети выходят за пределы государственного суверенитета и должны управляться непосредственно людьми.

Мы отдаем себе отчет в том, что представленное исследование не является всеобъемлющим. Более системный и обширный анализ доступных источников представляет исследовательский интерес, однако мы сознательно отказались от подобного подхода ${ }^{2}$. Настоящая статья представляет результаты качественного анализа ограниченного количества статей и монографий (академических и публицистических) по рассматриваемой проблематике, которые наглядно демонстрируют многообразие подходов к интерпретации понятия «суверенитет» в цифровой сфере, а также приписываемых ему идеологических характеристик. Базовым критерием отбора выступало использование понятия «суверенитет» в заглавии, аннотации или самом тексте статьи или монографии. В выборку не включались материалы, которые только косвенно относятся к рассматриваемой проблематике.

На наше исследование оказала влияние работа С. Пру [Proulx, 2007] о дискурсе «информационного общества» 1970-2000-х годов. Работа Пру [Ibid.] основана на конструктивистском подходе Криппендорфа [Krippendorf, 1993] к использованию метафор. Пру указывает на то, что «любая метафора, любой термин, используемый социальными акторами для описания существующей или воспринимаемой реальности, может стать предметом дискуссии», а также считает, что «метафоры формируют категории мышления субъекта» [Proulx, 2007, p. 113]. Используя этот подход, Пру рассматривает то, что сам называет «метафорой информационного общества», и указывает на многообразие акторов, использующих данный термин, а также на разницу в имеющихся идеологических предпосылках [Ibid.]. Следуя данному примеру, мы поставили цель рассмотреть «политику концепции» и проанализировать, кто, для каких целей и исходя

${ }^{2}$ Следуя полученным экспертным рекомендациям, мы осуществили более систематизированный поиск с применением инструментов WorldCat и ProQuest. Это открыло нам некоторые дополнительные возможности, а также показало, что отдельные работы, отобранные нами изначально, что особенно характерно для неакадемических работ, не отображаются в формируемых специальными поисковыми инструментами подборках. 
из каких предпосылок рассуждает о суверенитете. Настоящая статья призвана ответить на следующие вопросы: как термин «суверенитет» используется для понимания таких понятий, как «цифровые данные», «цифровые материалы» и «цифровая инфраструктура»? Как рассматриваемый термин соотносится (или не соотносится) с традиционным восприятием суверенности как свойства государства или с иными трактовками, которые связаны с категориями социальной справедливости, автономии или коллективного управления?

Мы начнем наш анализ с общего рассмотрения различных исторических и эпистемологических концепций суверенитета. Далее мы проанализируем подходы различных акторов к использованию понятия «суверенитет», например, рассмотрим, как в этом отношении ведут себя национальные государства, представители коренного населения, общественные организации, а также «отдельные личности» и «интернет-сообщество». Затем мы в общих чертах опишем общее и различное в рассмотренных подходах и покажем, что понятие «суверенитет» чаще всего используется для обозначения некой степени общественного контроля над цифровыми материалами и (или) инфраструктурой, а также как выражение сопротивления попыткам установления такого контроля, тогда как в отдельных случаях интерпретации и придаваемое суверенитету значение сильно различаются в зависимости от использующего понятие актора или группы.

\section{Постановка проблемы}

Прежде чем приступить к анализу примеров использования понятия «цифровой суверенитет» и других схожих терминов, необходимо рассмотреть процесс исторического и эпистемологического развития концепции суверенитета вне цифрового контекста. Современная трактовка суверенитета с точки зрения цифрового развития включает множество коллективных и индивидуальных концепций. Подобный плюрализм обусловлен разнообразием акторов, которые используют данный термин.

Термин «суверенитет» используется со времен Древнего Рима [Hinsley, 1986], однако его современная трактовка связана с именами Макиавелли, Гоббса, Бодена и Шмитта. Суверенитет обычно понимается как верховная власть над неким политическим образованием (политико-территориальной единицей). Стэнфордская энциклопедия философии [Philpott, 2003, p. 3] определяет четыре характеристики суверена: 1) он обладает властью; 2) его власть исходит от «признаваемого всеми источника легитимности» - от Бога, конституции или по праву наследования; 3) власть суверена является верховной; 4) власть суверена ограничена территориально. В отношении «территории» Холлис [Hollis, 2012] уточняет, что в данном случае имеется в виду не только поверхность суши, но и ресурсы, включая инфраструктуру, воздушное пространство, минеральное сырье под земной поверхностью или на континентальном шельфе. Филпотт [Philpott, 2003] подчеркивает, что наряду с принципом территориальности, который неразрывно связан с суверенностью, в прошлом огромное значение имела принадлежность к роду, кровному родству, конфессии, племени, феодальным отношениям. Территориальность суверенитета - то, что в рамках данной статьи понимается под государственным суверенитетом, - является неотъемлемой компонентой современной европейской политической мысли, для которой важнейшими категориями выступали права собственности в целом и право на владение землей в частности.

Концептуальное наполнение понятия «суверенитет» рассматривается с разных точек зрения. Некоторые авторы [Bhandar, 2011; Havercroft, 2011] указывают на то, что в условиях глобальной взаимозависимости установление абсолютного суверенитета 
представляется чрезвычайно трудным. Власть суверена может быть ограничена международными или региональными соглашениями, деятельностью транснациональных корпораций или вызовами планетарного масштаба, например, глобальным потеплением, пандемиями или, как в нашем случае, возникновением глобальных информационных сетей и Интернета. Другие авторы подчеркивают, что с точки зрения классического подхода установление суверенитета (создание национального государства) является абсолютной целью любой нации и, соответственно, основой всякой формы национализма, однако в современных реалиях, когда этнические меньшинства, лишенные возможности создать полноценное национальное государство, тем не менее претендуют на обладание хотя бы некой толикой суверенитета, эта цель представляется более комплексной, чем раньше. А. Аппадураи [Appadurai, 1990, p. 304] считает, что это «отличает нацию от государства». Именно многообразие всевозможных видов коллективной идентичности, которые стремятся к признанию в качестве отдельных наций и установлению собственного политического статуса как внутри существующих государственных границ, так и за их пределами, определяет комплексность современной глобальной политики. Это относится к тем политическим образованиям, в рамках которых на «государственный суверенитет» претендует значительная часть населения, но в то же время это справедливо и в отношении отдельных групп интересов, существующих внутри этих образований. Коренное население может обладать некой долей государственности в рамках территории своего проживания (например, территория Нунавут в Канаде) или выступать в качестве субъекта политического процесса в случае, когда принимаются решения относительно территории их проживания или находящихся там ресурсов.

Концепция суверенитета подвергается критике представителей коренных народов. Култхард [Coulthard, 2014] утверждает, что мирное сосуществование коренных народностей в рамках единых государств, созданных переселенцами, воспроизводит колонизаторскую, расистскую и патриархальную систему, которая формировалась для их подчинения. Он утверждает, что восприятие коренными народностями государственности ставит под вопрос «легитимность создаваемых переселенцами государственных образований и их претензии на установление власти над коренными жителями и их территориями, с одной стороны, и нормативную природу федеративного государства как приемлемой модели государственного устройства, с другой» [Coulthard, 2014, p. 36]. Автор статьи [Bonilla, 2017] в одном из недавних выпусков журнала "Cultural Anthropology”, посвященного проблематике суверенитета, утверждает, что суверенитет как политическая категория ассоциируется с насилием и неравенством и применялся для оправдания апроприации территорий так называемых несуверенных коренных народов через доктрину ничейной земли (terra nullius). Несмотря на то что позже все та же концепция суверенитета будет использоваться антиколониальными движениями, aвтор [Ibid.] настаивает на том, что сам по себе суверенитет не является нейтральным и что практика лишения прав материальной собственности, являющаяся неотъемлемой характеристикой международных отношений, точно так же является основной характеристикой суверенитета. В соответствии с тематикой настоящей статьи уместно поставить следующий вопрос: кто выдвигает определение технологического суверенитета и других схожих понятий и для какой цели?

Понятие «суверенитет» многократно трансформировалось, все больше отдаляясь от изначально приписываемых ему значений, что наложило отпечаток на концептуализацию понятий «цифровой суверенитет» и «технологический суверенитет». Возьмем в качестве примера понятие «продовольственный суверенитет», впервые употребленное международной фермерской организацией Via Campesina в 1996 г. и не- 
сколько позже определенное как «право каждой нации на здоровую и приемлемую с точки зрения традиций и культуры пищу, произведенную при помощи технологий, соответствующих требованиям экологичности и устойчивости, а также их право на самоопределение в вопросах развития продовольственных и сельскохозяйственных систем» [Declaration of Nyéléni, 2007]. Как мы убедимся далее, концепция продовольственного суверенитета стала предпосылкой к формированию движений за установление индивидуального или коллективного контроля над технологиями. «Суверенитет тела» как понятие также стал плодом деятельности групп активистов, для которых первостепенное значение имеет право распоряжения собственным телом. Например, одна из рассмотренных нами работ [Murphy, 2012] посвящена тому, как в 1970-е годы феминистки (преимущественно из числа белого населения) выступали за установление полного суверенитета женщины над ее собственным телом для дальнейшего контроля рождаемости. Исследовательница А. Вилсон, представительница коренных народностей [Wilson, 2015], заявляет, что «суверенитет тела и гендерное самоопределение» являются критически важными факторами преодоления системных форм угнетения. В данных примерах мы обнаруживаем смещение концепции суверенитета от коллективных форм выражения (государство, нация) к индивидуальным (отдельная личность или небольшая группа людей).

Некоторые исследователи [Werner, de Wilde, 2001] выступают за рассмотрение суверенитета с точки зрения лингвистики. Применяя теорию речевых актов Джона Серля (J.R. Searle), указанные авторы рассматривают понятие «суверенитет» скорее как «особую форму легитимизации», нежели как эмпирическую категорию, описывающую ситуацию абсолютного контроля над чем-либо. По их мнению, суверенитет представляет собой речевой акт, призванный установить или подтвердить позицию заявителя как обладателя абсолютной власти и придать легитимность фактам ее применения [Ibid., p. 287]. Авторы отмечают, что сам по себе дискурс о суверенитете не имеет места, когда власть и авторитет никем не оспариваются, что в наибольшей степени совпадает с распространенным толкованием суверенитета. С другой стороны, дискурс суверенитета возникает именно тогда, когда власть слабеет [Ibid., p. 307]. Как мы убедимся далее при рассмотрении концепции цифрового суверенитета, в США дискурс о суверенитете не развит именно потому, что США обладают наибольшим весом в вопросах управления Интернетом.

\section{Пять концепций цифрового суверенитета}

Далее мы представим результаты проведенного нами анализа пяти основных концепций цифрового суверенитета: «суверенитет киберпространства», «цифровой суверенитет государства и правительства», «цифровой суверенитет коренных народов», «цифровой суверенитет и общественные движения», а также «личный цифровой суверенитет». Перечисленные концепции были выделены для того, чтобы наилучшим образом продемонстрировать многообразие подходов к определению «цифрового суверенитета», а также определить ключевых акторов и особенности выдвигаемой ими повестки. Используемая нами методология не позволяет определить, какая из концепций количественно превалирует над другими (с точки зрения количества работ в каждой из них). По нашему мнению, значимость каждой категории должна оцениваться дискретно: вне всякого сомнения, претензии Китая и России на установление цифрового суверенитета сами по себе привлекут больше внимания со стороны академического сообщества или СМИ, чем проблемы суверенитета коренных народностей, что, однако, не дела- 
ет последнюю проблему менее важной. В нашем исследовании мы ориентировались в первую очередь на общий рост интереса к рассматриваемому понятию и многообразие существующих подходов.

Данная статья посвящена именно цифровому (курсив наш. - Примеч. пер.) суверенитету, но дискурс суверенитета и технологий существовал и до возникновения цифровых технологий как таковых. Например, в 1967 г. Научный совет Канады представил стратегию «технологического суверенитета», определив его как инструмент «развития и контроля над технологиями как средство поддержания национального суверенитета» [Globerman, 1978, p. 43]. Помимо прочих аспектов указанная стратегия подразумевала поощрение создания канадскими компаниями собственных технологических решений [Ibid.]. В то время поддержание технологического суверенитета имело скорее националистический подтекст, нежели являлось средством повышения экономической эффективности. Схожим образом в работе, посвященной политике Австралии по обеспечению технологического суверенитета [Grant, 1983], данное понятие трактовалось как «возможность и свобода определять, создавать, приобретать, внедрять на практике и использовать для получения выгоды технологии, необходимые для инновационного развития промышленности» [Ibid., p. 239]. В данном случае «свобода» подразумевает отсутствие каких-либо договорных или правовых препятствий, а «возможность» соответствующие знания и компетенции для создания технологических инноваций. Как мы сможем убедиться далее, указанные аспекты - свобода, возможность, национализм - до сих пор присутствуют в дискусе цифрового суверенитета с поправкой на большее внимание к вопросам контроля над данными.

\section{Суверенитет киберпространства}

Дискурс о суверенитете киберпространства зародился в 1990-е годы, однако рассматриваемая тема актуальна и по сей день. Центральной идеей данной категории является утверждение о том, что вопросы регулирования Интернета выходят за рамки государственного суверенитета. Лучше всего данную концепцию иллюстрирует Декларация независимости киберпространства Дж. Барлоу, написанная в 1996 г. Обратимся к первым строкам документа:

Правительства Индустриального Мира, Вы - утомленные гиганты плоти и стали, я пришел из Киберпространства, новой обители мышления. От имени будущего я прошу Вас из прошлого оставить нас наедине. Вас не звали к нам. Вы не имеете никакой власти там, где мы взрастаем [Barlow, 1996].

Декларация построена вокруг идеи о том, что Интернет является пространством особого типа, возникшим вне любой разновидности государственного контроля и, следовательно, должен таковым оставаться. Воззвание Барлоу стало ответом на действия со стороны государства по установлению контроля над цифровым пространством, в частности, на принятие в 1996 г. правительством США Закона о телекоммуникациях, целью которого было регулирование оборота порнографических и иных материалов непристойного содержания в Интернете [Barlow, 1996; Turner, 2006, p. 172]. В данном контексте суверенитет киберпространства выступает как противоположность государственного суверенитета. Как мы увидим далее, данная точка зрения в корне отличается от позиции, усердно продвигаемой Китаем и Россией, которые настаивают на реализации государственного суверенитета в Интернете, а также от аргументов приверженцев 
многостороннего управления Интернетом. В 1990-е годы претензии на установление суверенитета в киберпространстве подвергались критике [Wu, 1997], в частности, из-за ограниченности возможностей государств по контролю над физическими компонентами инфраструктуры Интернета. Также рассматривалась возможность реализации «минимального государственного суверенитета» в киберпространстве посредством выработки общего консенсуса относительно базовых стандартов Интернета [Ibid., p. 665].

Несмотря на некоторые различия в форме, идеи и концепции 1990-х годов актуальны и сейчас. В своей недавней работе Мильтон Мюллер (M. Mueller) pacкрывает концепцию «народного суверенитета» и утверждает, что основным носителем суверенитета в киберпространстве должны стать люди, которые пользуются Интернетом, а не национальные государства. Мюллер считает, что основой «народного суверенитета» должны стать существующие форматы многостороннего управления Интернетом, например, Форум по управлению Интернетом (Internet Governance Forum, IGF) и профильные организации, такие как Корпорация по присвоению доменных имен (ICANN). Концепция Мюллера значительно сложнее исходного посыла манифеста Барлоу, однако оба автора оспаривают идею государственного суверенитета в Интернете. О многосторонних институтах Мюллер пишет следующее:

«<Многосторонние институты > зачастую подменяют национальные правительства и тем самым в некотором роде становятся их прямыми конкурентами за верховную власть в вопросах регулирования сферы телекоммуникаций и информации» [Mueller, 2017, ch. 5].

Иные работы последних лет по интересующей нас проблематике также поддерживают идею о том, что вопросы управления средствами цифровой связи выходят за рамки или должны быть вне рамок государственного суверенитета. Бенджамин Браттон в работе "The Stack: On Software and Sovereignty" [Bratton, 2015] рассматривает взаимосвязи между концепцией суверенитета и рынком ПО. Браттон считает, что современная глобальная вычислительная инфраструктура - то, что он называет The Stack (стеллаж, колода. - Примеч. пер.), - подрывает основы, на которых выстраивался Вестфальский суверенитет национальных государств. Вестфальская система строилась на взаимоотношениях территориально ограниченных национальных государств в горизонтальной плоскости, тогда как The Stack основывается на принципиально иной логике функционирования суверенитета. В качестве примера Браттон рассматривает ситуацию 2010 г., когда между Никарагуа и Коста-Рикой едва не началась война из-за изменений в цифровом представлении границы между двумя государствами на Google Maps [Ibid., p. 120].

\section{Цифровой суверенитет, государства и правительства}

Некоторые авторы, например, Д.Х. Ху [Нu, 2015], настаивают на том, что, хотя Интернет и международные системы связи и рассматривались раньше как нечто, выходящее за пределы государственного суверенитета, с течением времени ситуация изменилась, во многом из-за появления облачных технологий, ставших свидетельством «возрождения суверенной власти в пространстве цифровых данных» [Hu, 2015, p. хіiі]. Цифровой суверенитет и связанные с ним понятия действительно активно обсуждаются на уровне государств и правительств. В иных случаях предметом обсуждения обычно становится контроль государств над потоками данных.

Одним из первых определение цифровому суверенитету дал французский бизнесмен Пьер Белланжер. В 2012 г. в своей публикации П. Белланжер определил цифровой 
суверенитет (souveraineté numérique) как «контроль над сегодняшним днем и нашей общей судьбой, которые являют себя и формируются через применение технологий и компьютерных сетей» ${ }^{3}$ [Bellanger, 2012, p. 154]. Белланжер отмечает, что ни Франция, ни Европа в целом не достигли достаточного уровня контроля и не обеспечили надлежащую независимость в вопросах развития цифровых сетей, и выступает за установление соответствующих экономических и правовых рамок, которые должны способствовать созданию собственных технологических инноваций. Данный подход во многом схож с националистическим подходом к «технологическому суверенитету», который был характерен для 1970-х и 1980-х годов - и работы тех лет, и позиция П. Белланжера строятся на приоритизации развития инновационных отраслей национальной экономики и создания соответствующих условий. Однако Белланжер выступает за цифровой суверенитет в контексте защиты частной жизни граждан европейских государств от «эксплуатации», в частности, за создание собственных национальных систем облачного хранения данных граждан. С этой точки зрения Белланжер близок ко многим другим современным исследователям, которые поддерживают необходимость установления государственного контроля над данными и системами связи, особенно подчеркивая необходимость снижения контроля со стороны иностранных государств, например, США ${ }^{4}$.

Правительства многих стран мира делали попытки повысить защищенность страны и граждан посредством поддержки развития «национальных» технологий и принятия соответствующих законов. Президент Бразилии Дилма Руссефф представила план вывода бразильского сегмента Интернета из-под влияния США и американских ИТкорпораций, что в некотором смысле может считаться попыткой реализации цифрового суверенитета [Rhodes, Armijo, 2014]. Германия инициировала процесс создания собственной системы обмена электронными сообщениями, прокладки новых подводных кабелей и начала продвигать политику локализации данных в качестве мер противодействия слежке США за телефонными переговорами и личной почтой канцлеpa Меркель [Maurer et al., 2015]. После взлома данных французского правительства в ходе предвыборной кампании 2017 г. Франция также направила средства на разработку шифруемого правительственного мессенджера с открытым кодом, что некоторые авторы рассматривают как попытку установления souveraineté technologique [Bergonhoux, 2018]. Отдельные авторы [Obar, Clement, 2013] обращаются к правительству Канады с призывом укрепить сетевой суверенитет страны путем развития инфраструктуры для перенаправления потоков данных, которые иначе направляются в США. Указанные авторы утверждают, что суверенитет находится под угрозой, когда «некое иностранное образование вмешивается во внутренние дела независимого государства» [Obar, Clement, 2013, p. 1].

Следует обратить внимание на понятие «суверенитет данных». После того, как Э. Сноуден представил на суд общественности данные внешней разведки США, эта тема приобрела особое значение в международном масштабе [Polatin-Reuben, Wright, 2014, p. 1]. Следует различать слабый суверенитет и сильный суверенитет: в первом случае подразумеваются «попытки частных компаний обеспечить защиту данных с осо-

\footnotetext{
${ }^{3}$ Перевод оригинального текста с французского на английский язык выполнен авторами статьи (Примеч. пер.).

${ }^{4}$ Один из авторов настоящей статьи [Couture, 2013] считает, что использование государствами и правительствами свободно распространяемого ПО с открытым программным кодом позволит обеспечить поддержание суверенитета над национальными информационными сетями и снизить зависимость от частных компаний.
} 
бым вниманием к защите цифровых прав» [Polatin-Reuben, Wright, 2014, p. 1], в то время как второй термин означает «меры государственной политики, направленные на защиту национальной безопасности» [Ibid.] ${ }^{5}$ Р Рассматривая политику стран БРИКС (Бразилия, Россия, Индия, Китай, ЮАР) с этой точки зрения, мы приходим к выводу, что Бразилия, Индия и ЮАР действуют в соответствии с политикой слабого суверенитета данных, тогда как Китай и Россия более склонны к политике сильного суверенитета. Политика сильного суверенитета данных может привести к сегментации Интернета (распад единого информационного пространства на ряд самостоятельных подсистем), однако она сопряжена со значительными издержками, возникающими вследствие цифровой и физической изоляции страны. Авторы, изучившие политику Индонезии в данной области [Nugraha, Sastrosubroto, 2015, p. 465], дают следующее определение суверенитету данных: «рациональные действия национальных государств, направленные на установление контроля над потоками конфиденциальных данных внутри собственных границ и за их пределами». Указанные авторы отмечают, что понятие «суверенитет данных» отсутствует в нормативных документах Индонезии, однако на деле такие аспекты суверенитета данных, как «шифрование, национальные службы обмена электронными сообщениями, локализация данных, регулирование национального интернет-трафика и базовая инфраструктура связи» [Nugraha, Sastrosubroto, 2015, p. 465], косвенно регулируются существующими законами.

Мы отмечаем, что позитивное восприятие суверенитета чаще всего встречается за пределами СШАㅎ․ В США понятие «цифровой суверенитет» (или иное схожее по смыслу) имеет негативную коннотацию. В качестве примера рассмотрим публикацию Rand Corporation, критикующую концепцию «цифрового суверенитета». В данном случае это понятие рассматривается как тождественное текущей политике Китая, направленной на ограничение доступа граждан к отдельным видам цифрового контента, что напрямую противоречит идее неограниченного и свободного Интернета, апологетом которой считаются США. Антагонизм Китая и стран Запада рассматривается во множестве работ. Политика «информационного суверенитета» Китая противопоставляется «свободному Интернету» стран Запада, при этом оба подхода нацелены на легитимизацию той или иной формы экономического глобализма - одна приносит непропорциональные выгоды Западу, а вторая призвана поддержать претензию государства на контроль информационных сетей [Powers, Jablonski, 2015, p. 203]. Другие работы [Budnitsky, Jia, 2018] указывают на то, что Китай и Россия занимаются продвижением концепции суверенного Интернета с 1998 г., что вновь вступает в противоречие со свободным Интернетом, который поддерживают американцы. В данном контексте «суверенный Интернет» является не только формой цифровой политики государства, но и своего рода элементом национальной идентичности, обращенным вовне. Подчеркивается, что нынешний дискурс, как и дискуссия о «технологическом суверенитете» 1970-х годов, выходит за рамки квазиправового определения суверенитета как верховной вла-

${ }^{5}$ Не пытаясь углубить рассмотренные определения, мы трактуем эти понятия следующим образом: слабый суверенитет подразумевает принуждение частных компаний к защите тайны частной жизни и личных данных пользователей, в то время как сильный суверенитет основывается на создании государством соответствующей инфраструктуры.

${ }^{6}$ Тем не менее ситуация может измениться. В своем недавнем интервью Стивен Бэннон, бывший советник президента США Д. Трампа, включил «цифровой суверенитет» в тройку ключевых факторов мирового развития. В его трактовке «цифровой суверенитет» является средством противодействия граждан «централизованному технократическому госкапитализму», то есть таким компаниям, как Google и Facebook, уличенным в присвоении интеллектуальной собственности [Barber, 2018] 
сти государства в пределах своей территории. Современный дискурс отражает особенности национального подхода к управлению и развитию Интернета, то есть является разновидностью национализма.

\section{Цифровой суверенитет коренных народов}

К понятию «суверенитет» обращаются и представители коренных народов. Для них «суверенитет» как концепция является частью более обширной дискуссии о праве коренных народов на абсолютный авторитет в вопросах управления территорией проживания, собственным телом и культурой. Составители сборника "Indigenous Data Sovereignty: Towards an Agenda” [Kukutai, Taylor, 2016] утверждают, что суверенитет данных реализуется «преимущественно органами государственной власти и транснациональными корпорациями» [Ibid., p. 2], вследствие чего права коренного населения в отношении «сбора, распоряжения и применения данных о гражданах, территории их проживания и образе жизни» [Ibid.] нередко игнорируются. Указанный сборник представляет результаты анализа множества примеров проявления самоопределения коренных народностей в вопросах управления цифровыми данными. В качестве примера рассмотрим одну из глав [Walter, 2016], автор которой утверждает, что проявление суверенитета коренных народов в вопросах управления цифровыми данными потребует создания собственной методики сбора этих данных, не связанной с колониальным прошлым, что будет способствовать изменению модели представления интересов коренного населения и порядка принятия решений. В другом разделе рассматривается процесс становления и особенности концепции суверенитета данных коренных народов на примере коренного населения Канады [First Nations Information Governance Center, 2016]. Представители коренных народов в определенный момент взяли на себя процесс собора недостающих данных, в частности, в ходе проведения общерегионального исследования состояния общественного здоровья они учредили торговую марку OCAР ${ }^{\circledR}$, аббревиатура которой расшифровывается как Ownership (владение), Control (управление), Access (доступ) и Possession (распоряжение). Таким образом, коренные народы стремятся установить контроль над важной информацией схожим образом с принятой моделью управления территориями, на которых они проживают [Ibid., p. 142]. В данном контексте проблема территориальной юрисдикции и управления информацией рассматривается через призму суверенитета.

В схожей манере автор монографии “Network Sovereignty: Building the Internet Across Indian Country” [Duarte, 2017] рассматривает проблематику взаимосвязей между информацией, информационно-коммуникационными технологиями (ИКТ) и коренными народами США. Он отмечает, что «для местных племен суверенитет напрямую связан с единством народа и эффективностью системы управления» [Ibid., p. 38]. В то же время автор утверждает, что многие коренные народности живут согласно «насильно навязанной или установленной в порядке уступки колониальной форме правления» [Ibid.], что в корне отличается от тех моделей самоуправления, которые были приняты ими ранее или могут быть реализованы на практике. Автор также разделяет культурный суверенитет и политико-правовой суверенитет и утверждает, что обмен информацией и продуктами творческого труда - важные компоненты суверенитета коренных народностей. Это форма накопления знаний о своей родной земле, философии, языках и космологии [Ibid., p. 37]. Коренные жители вынуждены прибегать к использованию ИКТ в интересах самоопределения и для эффективного самоуправления, при этом автор на конкретных примерах доказывает, что в коренных резервациях есть проблемы с 
доступом к цифровым технологиям, в частности, отмечается территориальная ограниченность сотового сигнала, скудность мультимедийного контента, связанного с местными культурами, проблематичность доступа к широкополосному Интернету и т.п. В заключительной части автор указывает на огромную значимость инфраструктурного развития в контексте активизации деятельности коренных народов, их самоопределения и полноценной реализации суверенитета.

\section{Общественные организации и цифровой суверенитет}

Рассматриваемые в данном разделе подходы к цифровому суверенитету сильно контрастируют с претензией государств на суверенитет в цифровом пространстве. Суверенитет в данном случае выступает в качестве средства обеспечения автономии общественных организаций, которая реализуется путем установления коллективного (в некоторых случаях - индивидуального) контроля над технологиями и цифровой инфраструктурой, а также за счет реализации имеющихся возможностей в деле разработки и применения инструментов, созданных этими движениями и (или) в их интересах. В данном контексте понятие «технологический суверенитет» чаще всего подразумевает использование открытого и свободно распространяемого ПО и услуг.

Во введении к настоящей статье мы указали на то, что именно через изучение подходов различных общественных движений и организаций мы стремимся продемонстрировать многообразие определений цифрового суверенитета. Общественные движения берут на вооружение концепцию цифрового суверенитета при обсуждении различных вопросов, связанных с технологическим развитием. Огромное влияние на нашу работу оказало двухтомное издание, опубликованное при поддержке французской общественной организации Ritimo [Haché, 2014a; 2014b; 2017]. В одной из рассматриваемых работ «технологический суверенитет» был определен как «технологии, разработанные гражданским обществом или в интересах гражданского общества» [Насhе́, 2014a, p. 11] 7. В данном контексте гражданское общество, зачастую понимаемое как тождественное общественному движению, определяется автором как объединение граждан или групп граждан, деятельность которых «определяется не соображениями выгоды, но удовлетворением потребностей и стремлений наряду с реализацией повестки общественной и политической трансформации» [Ibid.] . $^{8}$

В рамках представленного подхода реализация технологического суверенитета предполагает создание технологий, альтернативных военным и (или) коммерческим технологиям. Особое внимание уделяется свободно распространяемому программному обеспечению с открытым кодом и аппаратуре, которые являются основой технологического суверенитета. Таким образом, технологический суверенитет включает весь жизненный цикл технологии от момента добычи сырья до его утилизации. Большое значение придается соблюдению принципов устойчивого развития, а также общественным нормам, сопровождающим данный процесс [Haché, 2014a]. В качестве примеров общественных инициатив приводятся работы активистов в таких областях, как шифрование данных, организация децентрализованных общественных сетей и пространств для совместной работы ${ }^{9}$. Автор указанной работы предлагает рассматривать

\footnotetext{
${ }^{7}$ Перевод оригинального текста с французского на английский язык выполнен авторами статьи (Примеч. пер.).

${ }^{8}$ См. сноску 6.

${ }^{9}$ Один из рецензентов настоящей работы поставил вопрос о релевантности понятий «свободный» и «открытый» в рамках дискуссии о суверенитете, а также о том, может ли понятие «суверенитет» заменить собой первые два, и если да, то что служит предпосылкой для подобного перехода.
} 
технологический суверенитет так же, как трактуется понятие «продовольственный суверенитет»: ключевыми ценностными ориентирами в данном контексте выступают местные хозяйственные системы, устойчивые технологии и права людей в отношении контроля над технологическими системами. Эта концепция получает развитие в других работах, где технологический суверенитет рассматривается как форма эмансипации, «инструмент борьбы с номенклатурой в области информационных технологий, элемент более широкой повестки борьбы с империализмом» [Beltrán, 2016, p. 18].

Автор другого рассматриваемого нами сборника Numérique: Reprendre le contrôle («Цифровая индустрия: обретение контроля») [Nitot, 2016] обращается к проблематике пользования и владения личными данными. Хорошо известно, что мировые ИТгиганты, такие как Facebook и Google, используют данные пользователей для предоставления цифровых услуг, из чего неизбежно следует вывод о том, что эти данные фактически принадлежат не потребителям цифровых услуг, а их поставщикам. Нито считает, что дискуссия о технологическом суверенитете может сформировать предпосылки для возникновения новых практик, способных изменить модель взаимодействия потребителей и поставщиков цифровых услуг. По мнению автора, обладание суверенитетом над личными данными требует наличия соответствующей доли свободы и автономности [Ibid., p. 3].

Нито также отмечает, что важность проблематики технологического суверенитета не является очевидной. Повышение осведомленности широкой общественности о смысловом наполнении технологического суверенитета, в частности, о текущем состоянии цифровой индустрии, может способствовать усилению роли пользователей в вопросах распоряжения технологиями и данными. К примеру, Нито призывает взять на вооружение концепцию «конфиденциальности данных при использовании» (privacy by using) вместо распространенного подхода «встроенной защиты конфиденциальности данных» (privacy by design), что подразумевает не полный отказ от корпоративных технологий, а обеспечение надлежащей защиты от экспроприации данных силами самих пользователей. По мнению Нито, в настоящий момент пользователи цифровых услуг готовы к обсуждению назревающих изменений в цифровой экосистеме. Цифровые корпорации и национальные государства более не способны обеспечить должный уровень защищенности пользовательских данных, в связи с чем ответственность за сохранность данных должны нести сами пользователи.

Нетрудно определить основные моменты, в которых государства и гражданское общество не сходятся в восприятии цифрового суверенитета. По умолчанию можно предположить, что в условиях либеральной демократии государство и общество способны найти некие точки соприкосновения в данном вопросе, что нехарактерно для авторитарных режимов. Однако следует заметить, что даже так называемые либеральные демократии подчас склонны устраивать массовую слежку за своими гражданами, примеры чего хорошо известны. Общим моментом для всех публикаций, представляющих интересы гражданского общества в вопросах технологического суверенитета, является призыв к ограничению власти государств и корпораций над Интернетом. В качестве меры защиты членов общественных движений от государственной слежки рассматривается использование средств шифрования и автономных серверов. Тем не

Рассматриваемые нами в статье работы не дают четкого ответа на поставленные вопросы. Тем не менее мы утверждаем, что дискуссия о суверенитете не только органически включает проблематику свободного ПО, но и расширяет предметное поле за счет включения вопросов обеспечения неприкосновенности личных данных и устаревания технологий. Важнейшей характеристикой дискурса суверенитета также является связанность изучаемой проблематики с политической повесткой. 
менее данный подход не лишен слабых мест: авторы не учитывают, что те же коренные народности и жители стран «глобального Юга» подчас и вовсе лишены любой формы суверенитета, не только технологического, а также то, что представители цветного населения и мусульмане находятся под наблюдением со стороны государства значительно дольше, чем белое население (см., например, [Browne, 2015]).

\section{Личный цифровой суверенитет}

В данном разделе мы бы хотели подробнее остановиться на переходе от коллективного подхода к индивидуальному. Государственный суверенитет неразрывно связан с некой формой коллективности; в случае с гражданским обществом суверенитет схожим образом соотносится с неким абстрактным «мы». Отдельные личности могут прибегнуть к использованию свободного ПО и технологий шифрования в целях самозащиты, что и стало основой для выделения нами отдельной категории, связанной с деятельностью отдельных личностей.

Личный технологический суверенитет подразумевает установление индивидом контроля над собственными данными, устройствами, программным и аппаратным обеспечением и иными технологиями. До некоторой степени рассматриваемые в данном разделе работы коррелируют с упоминаемыми публикациями по проблематике цифрового суверенитета гражданского общества - в отдельных случаях особое внимание уделяется роли личности в процессе утверждения контроля над технологиями (в частности, за счет использования свободного ПО и технологий шифрования).

Концепция личного или персонального технологического суверенитета перекликается с феминистским дискурсом о суверенитете женщины в отношении собственного тела, который мы рассматривали в первом разделе работы. В данном случае проводится прямая параллель между распоряжением телом и определенной технологией. Автор публикации "Sexting Girls: Technological Sovereignty and the Digital” [Gill-Peterson, 2015] подчеркивает связь между конкретной технологией (в данном контексте - сотовыми телефонами) и возможностями девушек в отношении суверенитета над своим телом обладание суверенитетом определяет их право выбора в вопросе участия в переписке эротического содержания (так называемый секстинг (sexting), то есть отправка личных фотографий с явным сексуальным подтекстом). Хотя Гилл-Петерсон и выделяет ряд проблемных моментов, неизбежно связанных с секстингом, основной упор делается не на выставлении участвующих девушек в качестве жертв и необходимости их защиты от предусмотренных действующим законом санкций, а на их посреднической функции, которая рассматривается через призму технологического суверенитета как свойства их тел. Гилл-Петерсон критически оценивает концепцию цифрового суверенитета в контексте секстинга и приходит к выводу, что участвующие в подобном взаимодействии девушки утрачивают свой суверенитет, однако признает ошибочность рассмотрения вопроса о праве девушек на обладание технологическим суверенитетом исключительно в рамках бинарной модели «жертва - агент».

\section{Цифровой суверенитет: общее и различное}

Понятие «технологический суверенитет» используется еще с середины 1970-х годов, но начиная с 2011 г. наблюдается рост интереса к концепции «суверенитета» как такового. Далее мы представим наши главные выводы. 
Во-первых, хотя рассматриваемое понятие по-прежнему чаще всего используется при рассмотрении вопроса об осуществлении государством контроля над технологиями, в настоящее время его используют в своих интересах организации гражданского общества, представители коренных народностей и даже отдельные личности. Таким образом, мы обнаруживаем переход от коллективного трактования суверенитета как свойства, присущего государствам, к индивидуальному.

Во-вторых, мы определили, что в концепции технологического суверенитета сложились два подхода к восприятию независимости, контроля и автономности: 1) указанные понятия представляют собой возможности неких коллективных общностей (государств, сообществ, общественных движений и т.п.) в плане самостоятельного инновационного развития и (или) деятельного участия в развитии технологий (например, путем создания условий для появления собственных национальных технологий как формы выражения экономического национализма или распространения свободного ПО и автономной инфраструктуры на базе институтов и организаций гражданского общества); 2) защищенность конфиденциальных данных отдельных личностей или общностей, а также имеющийся уровень контроля над собственными данными, данными граждан или государства.

В-третьих, «суверенитет» как понятие обладает свойством риторической перформативности. Данный термин используется, в частности, как своего рода противоположность различным проявлениям гегемонизма, будь то гегемония США в международных отношениях (экономическое доминирование, их положение в системе управления Интернетом и т.д.), гегемония частных корпораций или переселенческая гегемония в отношениях между новоприбывшими и коренными народами. Ранее мы ссылались на одну из работ [Werner, Wilde, 2001], авторы которой указывают на то, что дискурс суверенитета тем более развит, чем сильнее номинальный авторитет отличается от реального. Во многих работах по рассматриваемой проблематике понятие «суверенитет» используется как противоположность ведущей роли США в управлении Интернетом или, что более характерно для современных публикаций, власти крупных ИТ-корпораций, в частности «большой пятерки»: Google, Amazon, Facebook, Apple и Microsoft (GAFAM). Риторическое измерение концепции цифрового суверенитета особенно хорошо иллюстрируют примеры Китая и России, которые используют данную концепцию как инструмент укрепления национального имиджа и продвижения собственной позиции в сфере управления Интернетом [Budnitsky, Jia, 2018].

В-четвертых, во многих случаях понятие «технологический суверенитет» служит для формирования неких альтернативных доминирующим подходам концепций. Мы отмечаем, что дискурс цифрового суверенитета практически не представлен в США, за исключением ситуаций, когда обсуждаются вопросы о суверенитете киберпространства, как в случае с заявлением экс-советника Бэннона, отстаивающего курс консервативных популистов. Хотя именно в США влияние интернет-сообщества и организаций, распространяющих свободное ПО, ощущается особенно сильно, они до сих пор, в отличие от европейских коллег, не выработали собственного понимания цифрового суверенитета. Следует отметить, что правительство США и в особенности американские компании по-прежнему сохраняют значительное влияние в системе управления Интернетом. На фоне нежелания большинства стран принимать меры для изменения статус-кво неизбежно возникает вопрос: почему они не представят на суд мировой общественности свое видение цифрового суверенитета?

Помимо неких общих моментов мы обнаруживаем множество расхождений в интерпретации цифрового суверенитета. Например, Китай продвигает особое видение суверенитета в интересах утверждения собственной легитимности в сфере контроля 
над информацией, тогда как организации гражданского общества, рассуждая о суверенитете, подразумевают защиту от организованной государством слежки или сбора коммерческих данных. Мы также отмечаем, что далеко не все акторы разделяют обеспокоенность представителей коренных народов вопросами колониальной и постколониальной политики. Можно ожидать, что рано или поздно повестка коренных народов вольется в общий дискурс усилиями прогрессивных социальных движений, однако в настоящий момент ситуация совершенно противоположная.

Остается открытым вопрос о взаимосвязях между различными терминами, рассмотренными в статье. Очевидно, что «суверенитет данных» относится в первую очередь к данным, а не к инфраструктуре (однако оба компонента неразрывно связаны). В чем же разница между «цифровым суверенитетом», «технологическим суверенитетом» или «интернет-суверенитетом»? Отчасти внешняя разница обусловлена различиями в социально-культурном контексте, откуда эти термины происходят, будь то английский или французский язык. Некоторые различия проявляются из-за приоритизации тех или иных аспектов проблемы, как, например, в случае с «технологическим суверенитетом» первостепенное значение имеют вопросы аппаратного обеспечения, a «интернет суверенитет» в первую очередь связан с мировой политической повесткой. Тем не менее отдельные гипотезы должны пройти проверку в рамках последующих исследований.

\section{Заключение. Цифровой суверенитет: опасения не напрасны?}

Термин «суверенитет» в последние годы все чаще употребляется в связке с такими понятиями, как «цифровой», «технологии», «данные», при этом различные акторы выдвигают на передний план разные аспекты проблемы. Рост интереса к «цифровому суверенитету» (или схожим по смыслу понятиям) может быть отчасти обусловлен такими факторами, как растущая значимость облачных технологий [Hu, 2015] и откровения Э. Сноудена о государственном и корпоративном шпионаже со стороны США [PolationReuben, Wright, 2014]. Повышенное внимание к цифровому суверенитету коррелирует с так называемым поворотом к суверенитету [Bonilla, 2017, p. 331] в социальных и гуманитарных науках. «Поворот» напрямую связан со сложившейся в мировом экспертном сообществе ситуацией и геополитическим контекстом, в рамках которых государства остаются важнейшими акторами, несмотря на распространенное убеждение в том, что происходит размытие государственных границ и упадок национальных государств. В отношении цифрового суверенитета современный дискурс должен учитывать многолетний опыт дискурса о технологическом детерминизме, утверждающего отмирание национальных государств по мере развития Интернета и формирования сетевого сообщества. Суверенитет как категория (или как «символ» [Ibid.]) также должен быть критически переосмыслен: сам по себе этот термин напрямую связан с историей западного колониализма и плотно укоренен в структуре международного права. Мы считаем необходимым переосмыслить опыт колониализма, который воспроизводится в том или ином виде, когда речь заходит о суверенитете, к чему призывают рассмотренные нами общественные организации и на чем строится позиция представителей коренных народов. Несмотря на то что понятие «цифровой суверенитет» подвергается критике как с эпистемологической точки зрения, так и по идеологическим соображениям, в дальнейшем нам еще только предстоит выработать некий целостный подход для того, чтобы осмыслить «поворот к суверенитету» в вопросах управления Интернетом и политики в области цифровых технологий в более общих категориях. Сейчас цифровой 
суверенитет может считаться востребованной и даже весьма практичной концепцией, однако многие вопросы, рассмотренные в рамках настоящей статьи, как правило, обсуждаются вне контекста наследия колониализма, империализма или критического переосмысления суверенитета как такового. Таким образом, вопрос состоит в следующем: что принесет нам цифровой суверенитет и что, наоборот, отнимет?

\section{Источники}

Appadurai A. (1990) Disjuncture and difference in the global cultural economy // Theory, Culture \& Society. No. 7 (2-3). P. 295-310.

Barber L. (2018) Steve Bannon Interview: FT future of news conference. Режим доступа: https://www.youtube.com/watch?v=vO9TyxqbHTI (дата обращения: 19.07.2019).

Barlow J.P. (1996) A Declaration of the Independence of Cyberspace // Electronic Frontier Foundation. 8 February. Режим доступа: https://www.eff.org/fr/cyberspace-independence (дата обращения: 19.07. 2019).

Bellanger P. (2012) De la souveraineté numérique // Le Débat. Vol. 170 (3). P. 149-159.

Beltrán N.C. (2016) Technological sovereignty: what chances for alternative practices to emerge in daily IT use // Hybrid. Revue des arts et médiations humaines. Режим доступа: https://www.semanticscholar.org/paper/Technological-Sovereignty\%3A-What-Chances-for-to inBeltran/b26e0d1f1c21497b2980f8515d6ce7948 d9c892f (дата обращения: 19.07.2019).

Bhandar B. (2011) The conceit of sovereignty: toward post-colonial technique // Stories Communities: Narratives of Contact and Arrival in Constituting Political Community / B. Lessard (ed.). Vancouver, BC, Canada: University of British Columbia Press. P. 66-88.

Bonilla Y. (2017) Unsettling sovereignty // Cultural Anthropology Vol. 32 (3). P. 330-339.

Bratton B.H. (2015) The Stack: On Software and Sovereignty (Software studies). Cambridge, MA: The MIT Press.

Browne S. (2015) Dark Matters: On the Surveillance of Blackness. Durham, NC: Duke University Press.

Budnitsky S., Jia L. (2018) Branding Internet sovereignty: digital media and the Chinese - Russian cyberalliance // European Journal of Cultural Studies. No. 21 (5). P. 594-613.

Coulthard S.G. (2014) Red Skin, White Masks: Rejecting the Colonial Politics of Recognition. Minneapolis, MN: University of Minnesota Press.

Couture S. (2013) Logiciels Libres: Réduction Des Coûts et Souveraineté Numérique. Note socioéconomique [Free Software: Cost Reduction and Digital Sovereignty. Socio-economic note]. Montréal: Institut de recherche et d'informations socio-économiques (IRIS). Режим доступа: http://www.iris-recherche.qc.ca/ wp-content/uploads/2013/09/Note-Logiciels-libres.pdf (дата обращения: 19.07.2019).

Couture S. (2018) Embedding social justice in Internet Infrastructures: sociotechnical proposals from civil society in the context of Internet Governance. In Presentation at the Canadian Communication Association Conference 30 May - 1 June 2018. Regina: University of Regina.

Couture S., King G., Toupin S. et al. (2016) "Another World Possible”? Reflections from the Media@McGill research delegation to the 2015 world social forum in Tunisia // Canadian Journal of Communication. Vol. 41 (1). P. $157-167$.

Duarte M.E. (2017) Network Sovereignty: Building the Internet across Indian Country. Seattle, WA: University of Washington Press.

First Nations Information Governance Centre. (2016) Pathways to First Nations' data and information sovereignty // Indigenous Data Sovereignty: Toward an Agenda (CAEPR) / T. Kukutai, J. Taylor (eds). Canberra, ACT, Australia: ANU Press. P. 139-156.

Gill-Peterson J. (2015) Sexting girls: technological sovereignty and the digital // Women \& Performance. No. 25 (2). P. 143-156. 
Globerman S. (1978) Canadian science policy and technological sovereignty // Canadian Public Policy. No. 4 (1). P. 34-45.

Grant P. (1983) Technological sovereignty: forgotten factor in the "Hi-Tech" Razzamatazz. Critical.

Haché A. (2014a) La souveraineté technologique. Dossier Ritimo. Режим доступа: https://www.ritimo.org/ IMG/pdf/dossier-st1.pdf (дата обращения: 19.07.2019).

Haché A. (2014b) Technological sovereignty // Mouvements. Vol. 79 (3). P. 38-48.

Haché A. (2017) Technological Sovereignty. Vol. 2. Barcelona. Режим доступа: https://www.ritimo.org/ IMG/pdf/sobtech2-en-with-covers-web-150dpi-2018-01-10.pdf (дата обращения: 19.07.2019).

Harold S.W., Libicki M.C., Cevallos A.S. (2016) Getting to Yes with China in Cyberspace. Santa Monica, CA: Rand Corporation. Режим доступа: https://www.rand.org/pubs/research_reports/ RR1335.html (дата обращения: 19.07.2019).

Havercroft J. (2011) The Captive of Sovereignty. Cambridge, MA: Cambridge University Press.

Hinsley F.H. (1986) Sovereignty. 2nd ed. Cambridge, MA: Cambridge University Press.

Hollis D.B. (2012) Stewardship Versus Sovereignty? International Law and the Apportionment of Cyberspace (ID 2038523, SSRN scholarly paper, 19 March). Rochester, NY: Social Science Research Network. Режим доступа: https://papers.ssrn.com/abstract=2038523 (дата обращения: 19.07.2019).

Hu T.H. (2015) A Prehistory of the Cloud. Cambridge, MA: The MIT Press.

Krippendorff K. (1993) Major metaphors of communication and some constructivist reflections on their use // Cybernetics \& Human Knowing. No. 2 (1). P. 3-25.

Kukutai T., Taylor J. (2016) Indigenous Data Sovereignty: Toward an Agenda (CAEPR). Canberra, ACT, Australia: ANU Press.

Maurer T., Skierka I., Morgus R. (2015) Technological sovereignty: missing the point? // 2015 7th International conference on Cyber conflict: Architectures in cyberspace (CyCon). P. 53-68 // IEEE. Режим доступа: http://ieeexplore.ieee.org/abstract/document/7158468/ (дата обращения: 19.07.2019).

Mueller M. (2017) Will the Internet Fragment?: Sovereignty, Globalization and Cyberspace. Malden, MA: Polity.

Murphy M. (2012) Seizing the Means of Reproduction: Entanglements of Feminism, Health, and Technoscience. Durham, NC: Duke University Press.

Nitot T. (2016) Numérique: reprendre le contrôle. Paris: Framasoft. Режим доступа: https://framabook.org/ docs/NRC/Numerique_ReprendreLeControle_CC-By_impress.pdf.

Nugraha Y.K., Sastrosubroto A.S. (2015) Towards data sovereignty in cyberspace // $20153^{\text {rd }}$ International conference on information and communication technology (ICoICT). Мау 2015. Р. 465-471. Режим доступа: https://ieeexplore.ieee.org/document/7231469 (дата обращения: 19.07.2019).

Obar J.A., Clement A. (2013) Internet Surveillance and Boomerang Routing: A Call for Canadian Network Sovereignty (ID 2311792, ssrn scholarly paper, 1 July). Rochester, NY: Social Science Research Network. Режим доступа: https://papers.ssrn.com/abstract=2311792 (дата обращения: 19.07.2019).

Peters B. (2016) Digital // Digital Keywords: A Vocabulary of Information Society and Culture / B. Peters (ed.). Princeton, NJ: Princeton University Press. P. 93-108.

Philpott D. (2003) Sovereignty. Stanford Encyclopedia of Philosophy Archive. 31 Мау. Режим доступа: https://plato.stanford.edu/archives/sum2016/entries/sovereignty/ (дата обращения: 19.07.2019).

Polatin-Reuben D., Wright J. (2014) An Internet with BRICS characteristics: data sovereignty and the Balkanisation of the Internet. Usenix. 7 July. Режим доступа: https://www.usenix.org/ system/files/conference/ foci14/foci14-polatin-reuben.pdf (дата обращения: 19.07.2019).

Powers S.M., Jablonski M. (2015) The Real Cyber War: The Political Economy of Internet Freedom. Urbana, IL: University of Illinois Press.

Proulx S. (2007) Interroger la métaphore d'une société de l'information: horizon et limites d'une utopie // Communication \& Langages. 152. P. 107-124. 
Rhodes S.D., Armijo L.E. (2014) Brazilian leadership and the global Internet // AULA Blog. Режим доступа: https://aulablog.net/tag/digital-sovereignty/ (дата обращения 19.07.2019).

Sélingué M. (2007) Forum for food sovereignty. Declaration of Nyéléni. 27 February. Режим доступа: https:// nyeleni.org/spip.php?article290 (дата обращения: 19.07.2019).

Toupin S. (2014) Feminist hackerspaces: the synthesis of feminist and hacker cultures // Journal of Peer Production. 5. P. 1-11.

Turner F. (2006) From Counterculture to Cyberculture: Stewart Brand, the Whole Earth Network, and the Rise of Digital Utopianism. Chicago, IL: University of Chicago Press.

Walter M. (2016) Data politics and Indigenous representation in Australian statistics // Indigenous Data Sovereignty: Toward an Agenda (CAEPR) / T. Kukutai, J. Taylor (eds). Canberra, ACT, Australia: ANU Press. P. 79-98.

Werner W.G., De Wilde J.H. (2001) The Endurance of sovereignty // European Journal of International Relations. Vol. 7 (3). P. $283-313$.

Wilson A. (2015) Our coming in stories: cree identity, body sovereignty and gender self-determination // Journal of Global Indigeneity 1: 4.

Wu T.S. (1997) Cyberspace sovereignty? The Internet and the international system // Harvard Journal of Law \& Technology. Vol. 10 (3). P. 647-666. 


\title{
What Does the Notion of "Sovereignty" Mean When Referring to the Digital?
}

\author{
S. Couture, S. Toupin
}

Stephane Couture - Bilingual Program in Communications, Glendon College, York University, 2275 Bayview Avenue, Toronto, ON, Canada M4N 3M6; E-mail: stephane.couture24@gmail.com

Sophie Toupin - Graduate Student in the Department of Art History and Communication Theory at McGill University (Montreal, Canada).

\begin{abstract}
This article analyzes how the notion of "sovereignty" has been and is still mobilized in the realm of the digital. This notion is increasingly used to describe various forms of independence, control, and autonomy over digital infrastructures, technologies, and data. Our analysis originates from our previous and current research with activist "tech collectives" where we observed a use of the notion to emphasize alternative technological practices in a way that significantly differs from a governmental policy perspective. In this article, we review several publications in order to show the difference, if not diverging ways in which the notion is being conceptualized, in particular by different groups. We show that while the notion is generally used to assert some form of collective control on digital content and/or infrastructures, the precise interpretations, subjects, meanings, and definitions of sovereignty can significantly differ.
\end{abstract}

Key words: Data sovereignty; digital sovereignty; discourses, indigenous peoples; Internet governance; nation-states; social movements; technological sovereignty

For citation: Couture S., Toupin S. (2020) What Does the Notion of "Sovereignty" Mean When Referring to the Digital? International Organisations Research Journal, vol. 15, no 4, pp. 48-69 (in Russian). DOI: 10.17323/19967845-2020-04-03

\section{References}

Appadurai A. (1990) Disjuncture and difference in the global cultural economy. Theory, Culture \& Society, 7 (2-3), pp. 295-310.

Barber L. (2018) Steve Bannon Interview: FT future of news conference. Available at: https://www.youtube.com/ watch?v=vO9TyxqbHTI (accessed 24 June 2018).

Barlow J.P. (1996) A Declaration of the Independence of Cyberspace. Electronic Frontier Foundation, 8 February. Available at: https://www.eff.org/fr/cyberspace-independence (accessed 14 November 2017).

Bellanger P. (2012) De la souveraineté numérique. Le Débat, 170 (3), pp. 149-159.

Beltrán N.C. (2016) Technological sovereignty: what chances for alternative practices to emerge in daily IT use? Hybrid. Revue des arts et médiations humaines. Available at: https://www. semanticscholar.org/paper/Technological-Sovereignty\%3A-What-Chances-for-to inBeltran/b26e0d1f1c21497b2980f8515d6ce7948d9c892f.

Bhandar B. (2011) The conceit of sovereignty: toward post-colonial technique. Stories Communities: Narratives of Contact and Arrival in Constituting Political Community (B. Lessard (ed.)). Vancouver, BC, Canada: University of British Columbia Press, pp. 66-88.

Bonilla Y. (2017) Unsettling sovereignty. Cultural Anthropology, 32 (3), pp. 330-339.

Bratton B.H. (2015) The Stack: On Software and Sovereignty (Software studies). Cambridge, MA: The MIT Press.

Browne S. (2015) Dark Matters: On the Surveillance of Blackness. Durham, NC: Duke University Press. 
Budnitsky S. and Jia L. (2018) Branding Internet sovereignty: digital media and the Chinese - Russian cyberalliance. European Journal of Cultural Studies, vol. 21 (5), pp. 594-613.

Coulthard S.G. (2014) Red Skin, White Masks: Rejecting the Colonial Politics of Recognition. Minneapolis, MN: University of Minnesota Press.

Couture S. (2013) Logiciels Libres: Réduction Des Coûts et Souveraineté Numérique. Note socioéconomique [Free Software: Cost Reduction and Digital Sovereignty. Socio-economic note]. Montréal: Institut de recherche et d'informations socio-économiques (IRIS). Available at: http://www.iris-recherche.qc.ca/wp-content/uploads/2013/09/Note-Logiciels-libres.pdf (accessed 25 July 2019).

Couture S. (2018) Embedding social justice in Internet Infrastructures: sociotechnical proposals from civil society in the context of Internet Governance. In Presentation at the Canadian Communication Association Conference 30 May - 1 June 2018. Regina: University of Regina.

Couture S., King G., and Toupin S., et al. (2016) "Another World Possible”? Reflections from the Media@ McGill research delegation to the 2015 world social forum in Tunisia. Canadian Journal of Communication, 41 (1), pp. 157-167.

Duarte M.E. (2017) Network Sovereignty: Building the Internet across Indian Country. Seattle, WA: University of Washington Press.

First Nations Information Governance Centre. (2016) Pathways to First Nations' data and information sovereignty. Indigenous Data Sovereignty: Toward an Agenda (CAEPR) (T. Kukutai, J. Taylor (eds)). Canberra, ACT, Australia: ANU Press, pp. 139-156.

Gill-Peterson J. (2015) Sexting girls: technological sovereignty and the digital. Women \& Performance, 25 (2), pp. 143-156.

Globerman S. (1978) Canadian science policy and technological sovereignty. Canadian Public Policy/Analyse De Politiques 4 (1), pp. 34-45.

Grant P. (1983) Technological sovereignty: forgotten factor in the "Hi-Tech" Razzamatazz. Critical.

Haché A. (2014a) La souveraineté technologique. Dossier Ritimo. Available at: https://www.ritimo.org/IMG/ pdf/dossier-st1.pdf

Haché A. (2014b) Technological sovereignty. Mouvements, 79 (3), pp. 38-48.

Haché A. (2017) Technological Sovereignty, vol. 2. Barcelona. Available at: https://www.ritimo.org/IMG/pdf/ sobtech2-en-with-covers-web-150dpi-2018-01-10.pdf

Harold S.W., Libicki M.C., Cevallos A.S. (2016) Getting to Yes with China in Cyberspace. Santa Monica, CA: Rand Corporation. Available at: https://www.rand.org/pubs/research_reports/ RR1335.html (accessed 22 June 2018).

Havercroft J. (2011) The Captive of Sovereignty. Cambridge, MA: Cambridge University Press.

Hinsley F.H. (1986) Sovereignty. 2nd ed. Cambridge, MA: Cambridge University Press.

Hollis D.B. (2012) Stewardship Versus Sovereignty? International Law and the Apportionment of Cyberspace (ID 2038523, SSRN scholarly paper, 19 March). Rochester, NY: Social Science Research Network. Available at: https://papers.ssrn.com/abstract=2038523 (accessed 21 September 2017).

Hu T.H. (2015) A Prehistory of the Cloud. Cambridge, MA: The MIT Press.

Krippendorff K. (1993) Major metaphors of communication and some constructivist reflections on their use. Cybernetics \& Human Knowing, 2 (1), pp. 3-25.

Kukutai T., Taylor J. (2016) Indigenous Data Sovereignty: Toward an Agenda (CAEPR). Canberra, ACT, Australia: ANU Press.

Maurer T., Skierka I., Morgus R. (2015) Technological sovereignty: missing the point? 2015 7th International conference on Cyber conflict: Architectures in cyberspace (CyCon), pp. 53-68. IEEE. Available at: http://ieeexplore.ieee.org/abstract/document/7158468/ (accessed 18 September 2017).

Mueller M. (2017) Will the Internet Fragment?: Sovereignty, Globalization and Cyberspace. Malden, MA: Polity.

Murphy M. (2012) Seizing the Means of Reproduction: Entanglements of Feminism, Health, and Technoscience. Durham, NC: Duke University Press. 
Nitot T. (2016) Numérique: reprendre le contrôle. Paris: Framasoft. Available at: https://framabook.org/docs/ NRC/Numerique_ReprendreLeControle_CC-By_impress.pdf.

Nugraha Y.K., Sastrosubroto A.S. (2015) Towards data sovereignty in cyberspace. 2015 3rd International conference on information and communication technology (ICoICT), May 2015, pp. 465-471. Available at: https:// ieeexplore.ieee.org/document/7231469

Obar J.A., Clement A. (2013) Internet Surveillance and Boomerang Routing: A Call for Canadian Network Sovereignty (ID 2311792, ssrn scholarly paper, 1 July). Rochester, NY: Social Science Research Network. Available at: https://papers.ssrn.com/abstract=2311792 (accessed 24 June 2018).

Peters B. (2016) Digital. (B. Peters (ed.)) Digital Keywords: A Vocabulary of Information Society and Culture. Princeton, NJ: Princeton University Press, pp. 93-108.

Philpott D. (2003) Sovereignty. Stanford Encyclopedia of Philosophy Archive, 31 May. Available at: https://plato. stanford.edu/archives/sum2016/entries/sovereignty/ (accessed 24 June 2018).

Polatin-Reuben D., Wright J. (2014) An Internet with BRICS characteristics: data sovereignty and the Balkanisation of the Internet. Usenix, 7 July. Available at: https://www.usenix.org/ system/files/conference/foci14/ foci14-polatin-reuben.pdf

Powers S.M., Jablonski M. (2015) The Real Cyber War: The Political Economy of Internet Freedom. Urbana, IL: University of Illinois Press.

Proulx S. (2007) Interroger la métaphore d'une société de l'information: horizon et limites d'une utopie. Communication \& Langages, 152, pp. 107-124.

Rhodes S.D., Armijo L.E. (2014) Brazilian leadership and the global Internet. AULA Blog. Available at: https:// aulablog.net/tag/digital-sovereignty/ (accessed 14 November 2017).

Sélingué M. (2007) Forum for food sovereignty. Declaration of Nyéléni, 27 February. Available at: https://nyeleni. org/spip.php?article290 (accessed 22 June 2018). Studies in Innovation, 1 (2), pp. 239-270.

Toupin S. (2014) Feminist hackerspaces: the synthesis of feminist and hacker cultures. Journal of Peer Production, 5, pp. 1-11.

Turner F. (2006) From Counterculture to Cyberculture: Stewart Brand, the Whole Earth Network, and the Rise of Digital Utopianism. Chicago, IL: University of Chicago Press.

Walter M. (2016) Data politics and Indigenous representation in Australian statistics. Indigenous Data Sovereignty: Toward an Agenda (CAEPR) (T. Kukutai, J. Taylor (eds)). Canberra, ACT, Australia: ANU Press, pp. 79-98.

Werner W.G., De Wilde J.H. (2001) The Endurance of sovereignty. European Journal of International Relations, 7 (3), pp. 283-313.

Wilson A. (2015) Our coming in stories: cree identity, body sovereignty and gender self-determination. Journal of Global Indigeneity, 1: 4.

Wu T.S. (1997) Cyberspace sovereignty? The Internet and the international system. Harvard Journal of Law \& Technology, 10 (3), pp. 647-666. 